\title{
Combination of Multi-Energy Calibration (MEC) and Laser-Induced Breakdown Spectroscopy (LIBS) for Dietary Supplements Analysis and Determination of $\mathrm{Ca}, \mathrm{Mg}$ and $\mathrm{K}$
}

\author{
Amanda S. Augusto, ${ }^{a}$ Jeyne P. Castro, ${ }^{a}$ Marco A. Sperança ${ }^{a}$ and \\ Edenir R. Pereira-Filho ${ }^{\circledR} * a$ \\ ${ }^{a}$ Grupo de Análise Instrumental Aplicada (GAIA), Departamento de Química, \\ Universidade Federal de São Carlos, 13565-905 São Carlos-SP, Brazil
}

\begin{abstract}
This study describes the application of laser-induced breakdown spectroscopy (LIBS) for the direct determination of $\mathrm{Ca}, \mathrm{K}$ and $\mathrm{Mg}$ in powdered dietary supplements. Multi-energy calibration (MEC) method was applied to obtain a calibration curve. With MEC, it was possible to observe spectral interferences and select adequate emission lines from LIBS. For $\mathrm{Ca}$ and $\mathrm{Mg}$, five lines were selected and for $\mathrm{K}$ just two lines among four could be selected (compromising the results). The trueness for dietary supplements ranged from 81 to $103 \%$ for $\mathrm{Ca}$ and 74 to $106 \%$ for $\mathrm{Mg}$. For $\mathrm{K}$, just the samples S3 (95\%) and S5 (109\%) showed acceptable trueness values. In the case of Ca and $\mathrm{K}$, besides the MEC, the normalization using $\mathrm{C}$ as internal standard also improved the figure of merit results. The MEC and normalization processes showed that possible matrix effect and spectral interferences could be avoided, and the results of trueness and precision were satisfactory.
\end{abstract}

Keywords: multi-energy calibration, direct solid analysis, dietary supplements, LIBS, macronutrients determination

\section{Introduction}

The most exploited aspect in analytical chemistry is related to quantitative analysis. These analyses are mainly based on modern instrumental techniques, which are able to record analytical signals intensities for a single analyte in a short time interval. The majority of analytical procedures employ aqueous samples and standards and a myriad of calibration strategies is routinely available in the literature. The most common and successfully employed one is external calibration, where several standard solutions with different concentrations of the analyte is used to propose a linear model using analyte standard concentrations in $x$-axis and signal intensities in $y$-axis. Afterwards, a linear model is calculated and used to obtain the analyte concentration of samples and some figures of merit, such as limits of detection (LOD) and quantification (LOQ) ${ }^{1,2}$

The limitation of external calibration is the fact that full analyte selectivity is required and the influence of sample matrix must be negligible. ${ }^{1}$ In all cases reported in the literature, an intense sample preparation procedure is required. These procedures include wet digestion protocols

*e-mail: erpf@ufscar.br that employ a simple sample dissolution (feasible in few cases), ${ }^{3-7}$ digester block $^{8-12}$ or microwave oven assisted digestion. ${ }^{3,5,13-15}$ Results from samples with a complex matrix can be strongly affected if the differences between sample and standard matrices are neglected. Beside the external calibration, alternatives such as internal standard (IS) method ${ }^{16-19}$ and standard addition method ${ }^{20-24}$ are often used in analytical chemistry.

All the traditional calibration methods previously mentioned present drawbacks for analysis of complex samples, being in some cases necessary the application of other strategies such as multivariate calibration ${ }^{25-29}$ and matrix-matching procedures. ${ }^{30-32}$

Since 2011, nontraditional calibration methods, such as standard dilution analysis (SDA), ${ }^{30-33}$ interference standard method (ISM) ${ }^{34-36}$ and multi-energy calibration (MEC), ${ }^{37}$ have been applied for quantitative analysis by inductively coupled plasma (ICP) optical emission spectrometry (OES), high-resolution continuum source (HR-CS) flame atomic absorption spectrometry (FAAS), ICP-mass spectrometry (MS) and microwave induced plasma (MIP) with OES.

According to Virgilio et al. ${ }^{37} \mathrm{MEC}$ is a method where the signal intensity for a wavelength can be directly correlated to the concentration of the analyte and the 
excited-state of energy. In the procedure proposed by Virgilio et al. ${ }^{37}$ a simple and efficient matrix-matching procedure was proposed for several types of samples after wet digestion or dissolution (e.g., green tea, beer, red wine, apple juice, cola soft drink, vinegar, ethanol fuel and creek water) using ICP OES, HR-CS FAAS and MIP OES.

As widely reported in the scientific literature, a matrixmatching procedure in analysis is essential, mainly for complex samples, as food. These difficulties are even higher when direct solid sample analysis is performed, and several strategies are reported in the literature. ${ }^{16,17,38}$

Beyond the matrix complexity, most samples require an acid digestion process to be analyzed by conventional techniques. During sample preparation, errors can be introduced due to the several unitary operations, such as dilution and acid addition that compromise analytical frequency increasing the contamination possibilities and generating residues. ${ }^{39}$

Sample preparation processes can be avoided or minimized when analytical techniques that allow the direct solid sample analysis are applied, being laser-induced breakdown spectroscopy (LIBS) one alternative. ${ }^{40-43}$ Besides the advantage mentioned, the LIBS analysis has high analytical frequency, requires reduced sample mass (typically less than $100 \mathrm{mg}$ ), and has multi-element capability when compared with FAAS. ${ }^{42}$

On the other hand, disadvantages related to calibration method are observed because the ablation process involves some $\mu \mathrm{g}$ of samples. Reference material with certified values concentration for masses in this range or lower are not commercially available. ${ }^{38,44,45}$ Direct solid analysis also presents difficulties, such as the data reproducibility related to the ablation process, formation of the plasma, microheterogeneity and matrix effects, which in some cases can be minimized applying several types of normalizations or standardization on the raw data. ${ }^{46}$

In the present study, a simple and fast method for the direct analysis of powdered samples of dietary supplements by LIBS to determine $\mathrm{Ca}, \mathrm{Mg}$ and $\mathrm{K}$ was applied and discussed. The dietary supplements, including those analyzed in this study, are commonly used in the sense of compensate possible deficiencies in macro- and trace elements. These products are prepared synthetically in laboratories with the addition, for example, of powdered milk, maltodextrin, sucrose, cellulose, vitamins (i.e., ascorbic acid) and minerals (i.e., calcium carbonate $\left(\mathrm{CaCO}_{3}\right)$, calcium phosphate, magnesium carbonate $\left(\mathrm{MgCO}_{3}\right)$, magnesium phosphate, potassium iodide (KI)). The spectra obtained from LIBS technique present several emission lines allowing to explore the MEC capability as a strategy to obtain the concentration values and circumvent problems related to matrix effects. Also, several types of normalization modes, including the use of IS naturally presented in the sample (mainly carbon), were tested to improve figures of merit.

\section{Experimental}

Reagents, sample description and reference values acquisition

The reagents used throughout the study were of analytical grade and higher purity. For the ICP OES analysis the water used was deionized using a Milli-Q ${ }^{\circledR}$ Plus Total Water System (18.2 M $\Omega$ cm resistivity; Millipore Corp., Bedford, MA, USA). All flasks (polypropylene (PP)) and glassware were previously decontaminated by soaking into a $10 \% \mathrm{v} \mathrm{v}^{-1} \mathrm{HNO}_{3}$ solution for $24 \mathrm{~h}$ and rinsed with deionized water afterwards. Multi-element standard solutions were prepared daily after successive dilutions of stock solutions: $10,000 \mathrm{mg} \mathrm{L}^{-1} \mathrm{Ca}$, and $1,000 \mathrm{mg} \mathrm{L}^{-1} \mathrm{~K}$ and $\mathrm{Mg}$ (Quemis, Jundiaí, SP, Brazil). These multi-element solutions were used to prepare the calibration curves to obtain reference concentration values in ICP OES determinations. Six commercial solid dietary supplements (S1-S6) were analyzed and further details about the intended use can be found elsewhere. ${ }^{28}$

For the ICP OES determinations, the solid samples were submitted to wet digestions with the assistance of a microwave equipment, employing analytical grade concentrated (14 mol L-1) $\mathrm{HNO}_{3}$ (Synth, Diadema, SP, Brazil) that was previously sub-boiled with a Distillacid ${ }^{\mathrm{TM}}$ BSB939-IR sub-boiling system (Berghof, Eningen, Germany) and $30 \% \mathrm{~m} \mathrm{v}^{-1} \mathrm{H}_{2} \mathrm{O}_{2}$ (Synth) was used as auxiliary oxidant reagent. Speedwave Four microwave system (Berghof) used was equipped with eight high pressure with eight high-pressure TFM ${ }^{\circledR}$ vessels (DAK100). The acid digestion procedure was accomplished with $500 \mathrm{mg}$ sample (pellets used for the LIBS analysis), $6 \mathrm{~mL}$ of $\mathrm{HNO}_{3}\left(2 \mathrm{~mol} \mathrm{~L}^{-1}\right)$ and $3 \mathrm{~mL}$ of $\mathrm{H}_{2} \mathrm{O}_{2}$. The heating program is described in Table $\mathrm{S} 1$ (Supplementary Information (SI) section).

The measurements were performed by Thermo iCAP 7000 ICP OES system (Thermo Fisher Scientific, Madison, MT, USA) and an external calibration was applied to obtain the reference concentration values of $\mathrm{Ca}, \mathrm{K}$ and $\mathrm{Mg}$ in the dietary supplements samples. All operational parameters from this system are shown in Table S2 (SI section).

\section{LIBS instrumentation and solid sample preparation}

The LIBS instrument used in the present study is a commercial benchtop system, model J200 (Applied 
Spectra, Freemont, CA, USA). The system is equipped with a 1064-nm neodymium-doped yttrium aluminum garnet (Nd:YAG) laser with a pulse duration of $8 \mathrm{~ns}$. The spectrometer is a 6-channel charged coupled device (CCD) with 12,288 pixels ranging from 186 to $1042 \mathrm{~nm}$. The operational conditions of the LIBS instrument can be varied in the following ranges: (i) gate delay from 0 to $2 \mu$ s; (ii) laser pulse energy from 0 to $100 \mathrm{~mJ}$; (iii) spot size from 50 to $250 \mu \mathrm{m}$; (iv) gate width is fixed in $1.05 \mathrm{~ms}$; and (v) laser pulse repetition rate, adjustable from 1 to $10 \mathrm{~Hz}$.

With the combination of these parameters the laser pulse irradiance $\left(\mathrm{GW} \mathrm{cm} \mathrm{cm}^{-2}\right)$ and fluence $\left(\mathrm{mJ} \mathrm{cm}^{-2}\right)$ can range from $0.255 \mathrm{GW} \mathrm{cm}^{-2}$ and $2 \mathrm{~mJ} \mathrm{~cm}^{-2}(250 \mu \mathrm{m}$ spot size and $1 \mathrm{~mJ}$ laser pulse energy) to $636.62 \mathrm{GW} \mathrm{cm}^{-2}$ and $5093 \mathrm{~mJ} \mathrm{~cm}^{-2}$ (50 $\mu \mathrm{m}$ spot size and $100 \mathrm{~mJ}$ laser pulse energy). The power ranges from $125 \mathrm{~kW}$ ( $1 \mathrm{~mJ}$ laser pulse energy) to $12.5 \mathrm{MW}$ (100 mJ laser pulse energy).

Several different food matrices are currently analyzed in our research group using this instrument and the conditions are well stablished with several examples obtained in the last 3 years. ${ }^{12,28,44}$ In this way, Table 1 shows an instrumental condition that permitted good reproducibility, no signal saturation for major constituents and high analytical frequency.

Table 1. Experimental conditions for the J200 LIBS measurements

\begin{tabular}{lc}
\hline Parameter & Value \\
\hline Delay time / $\mu \mathrm{s}$ & 0.5 \\
Spot size / $\mu \mathrm{m}$ & 50 \\
Laser pulse energy / $\mathrm{mJ}$ & 50 \\
Fluence / $\left(\mathrm{mJ} \mathrm{cm}^{-2}\right)$ & 2546 \\
Irradiance / $\left(\mathrm{GW} \mathrm{cm}^{-2}\right)$ & 318 \\
Sample speed / $\left(\mathrm{mm} \mathrm{s}^{-1}\right)$ & 1 \\
Laser repetition rate / Hz & 10 \\
Number of scan lines & 20 \\
Distance between lines / mm & 0.5 \\
Approximate number of laser pulses per line & 70 \\
Total spectra recorded per pellet & around 1400 \\
\hline
\end{tabular}

In order to perform the LIBS measurements and following MEC assessment, $\mathrm{CaCO}_{3}\left(100.09 \mathrm{~g} \mathrm{~mol}^{-1}\right.$, Mallinckrodt, Staines-upon-Thames, UK), $\mathrm{MgCO}_{3}$ (84.32 $\mathrm{g} \mathrm{mol}^{-1}$, ECIBRA, Curitiba, PR, Brazil), KI (166.00 $\mathrm{g} \mathrm{mol}^{-1}$, Synth), and microcrystalline cellulose $\left(\mathrm{C}_{6} \mathrm{H}_{10} \mathrm{O}_{5}, 324.3 \mathrm{~g} \mathrm{~mol}^{-1}\right.$, density: 0.26-0.34 $\mathrm{g} \mathrm{cm}^{-3}$; Synth) were used to prepare standards and pelletized.

In this study, cellulose was considered as blank and for the standards, a solid mixture with cellulose was previously prepared to obtain an intermediary stock solid mixture. The final $\mathrm{Ca}, \mathrm{K}$ and $\mathrm{Mg}$ concentrations were $0.707,0.595$ and $0.182 \% \mathrm{~m} \mathrm{~m}^{-1}$.

For MEC assessment, two solid mixtures (pellets) are needed: (i) pellet 1 (sample plus blank (microcrystalline cellulose)); and (ii) pellet 2 (sample plus stock mixture (microcrystalline cellulose and the salts of $\mathrm{Ca}, \mathrm{K}$ and $\mathrm{Mg}$ )).

For all samples preparation, $250 \mathrm{mg}$ of each one was mixed in a mortar with $250 \mathrm{mg}$ of cellulose (pellet 1: sample + blank) or $250 \mathrm{mg}$ of standard stock solid mixture (pellet 2: sample + standard), then pelletized using about $10 \mathrm{t} \mathrm{inch}^{-1}$ of pressure with a pressing machine. All pellets were made in triplicate. In total, for the six samples, 72 pellets were prepared. Figure 1 shows all the procedure mentioned in this section.

Additional tests were performed changing the proportion of the analytes in the stock mixture. In this case, four mixtures were prepared with the following concentrations (in \%): (i) Ca 0.66, K 0.68, Mg 0.18; (ii) Ca 0.35, K 0.60, $\mathrm{Mg} 0.18$; (iii) Ca 0.72, K 0.26, Mg 0.18; and (iv) Ca 0.72, $\mathrm{K} 0.59, \mathrm{Mg} \mathrm{0.09}$. The goal of this test was to observe if the MEC approach can correct different analytes proportions in the standard mixture.

The data treatment was performed in Microsoft Excel $^{\circledR}$ and MATLAB 2017b. ${ }^{47}$

\section{Results and Discussion}

As mentioned before, new calibration strategies such as MEC can be applied to avoid difficulties related to sample
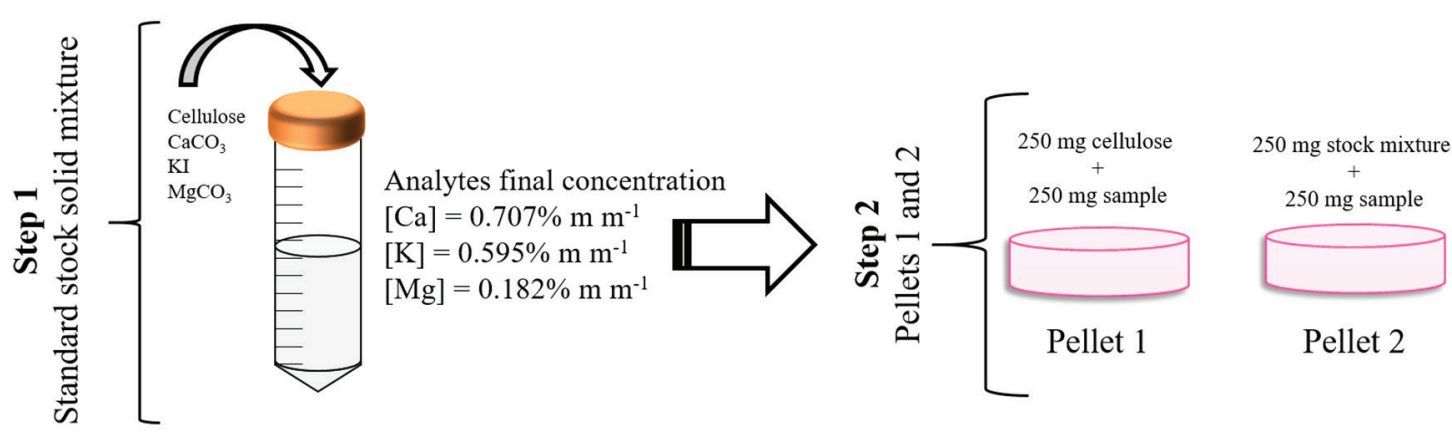

Figure 1. Sample preparation procedure for LIBS analysis using MEC. 
matrix, since this strategy is based on a matrix-matching process. In this sense, MEC is a new alternative for solid analysis by LIBS. Figure 1 shows that the amount of sample added in both pellets ( 1 and 2 ) is the same. Direct solid analysis using LIBS is strongly affected by matrix interferences, mainly for food samples, which is a complex matrix due to their organic compounds such as lipids, carbohydrates and proteins. ${ }^{48}$

LIBS analysis can provide a lot of spectral information and chemometric tools are required to assess and improve the results. In this way, before MEC, twelve normalization modes were also applied to the raw spectral information of each sample and standards.

In this section, the twelve normalizations were codified as 1 (average), 2 (norm and average), 3 (area and average), 4 (individual spectrum maximum and average), 5 (sum), 6 (norm and sum), 7 (area and sum), 8 (individual spectrum maximum and sum), 9 (C I $193.09 \mathrm{~nm}$ (atomic line) as internal standard (IS) and average), 10 (C I $193.09 \mathrm{~nm}$ as IS and sum), 11 (C I $247.85 \mathrm{~nm}$ (atomic line) as IS and average) and 12 (C I $247.85 \mathrm{~nm}$ as IS and sum). It is important to mention that the normalization number 1 is only the average of all analytical signals. Our research group is investigating these standardization strategies since 2016 and detailed information can be assessed in the studies published by Castro and Pereira-Filho ${ }^{46}$ and Sperança et al. ${ }^{49}$

After data normalizations, values of area and height were calculated for each analyte and the MEC was applied for selected emission lines. At the first attempt, eight emission lines for $\mathrm{Ca}$ and $\mathrm{Mg}$, and four for $\mathrm{K}$ were evaluated, considering those that presented the highest relative intensity. Due to the capability of MEC to identify spectral interferences, few emission lines were removed to improve the statistical parameters (determination coefficient, $\mathrm{R}^{2}$ ) of the calculated linear models. Figure 2 shows an example using sample $\mathrm{S} 1$. This figure shows the selected emission lines for each analyte: sample + cellulose $(y$-axis, pellet 1$)$ and sample + standard ( $x$-axis, pellet 2$)$ and linear model for the signal height normalized by norms 9, 11 and 8 for $\mathrm{Ca}, \mathrm{K}$ and $\mathrm{Mg}$, respectively.

As can be noted in Figures 2a and 2b, five emission lines were selected for $\mathrm{Ca}$. As expected, $\mathrm{Ca}$ signals in the pellet 2 (sample + standard) are greater than those observed for pellet 1 (sample + cellulose). From the eight emission lines tested, two presented spectral interferences ( 396.84 and $215.88 \mathrm{~nm}$ ) and the line $534.94 \mathrm{~nm}$ presented low intensity signal. Four figures of merit were calculated for each sample and for each normalization mode: slope from the linear model, uncertainty with $95 \%$ of confidence level $(\mathrm{n}=3)$, relative standard deviation $(\mathrm{RSD}, \mathrm{n}=3)$ and trueness calculated after comparison between the reference
(ICP OES) and predicted concentrations. The slope was calculated according to the linear model stablished for each sample as depicted in Figures $2 \mathrm{~b}(\mathrm{Ca}), 2 \mathrm{~d}(\mathrm{~K})$ and $2 \mathrm{f}(\mathrm{Mg})$.

LIBS concentration values $\left(\mathrm{C}^{\mathrm{Sam}}\right)$ for each analyte, sample and normalization were calculated by equation 1 .

$\mathrm{C}^{\mathrm{Sam}}=\frac{\text { slope } \times \mathrm{C}^{\mathrm{Std}}}{(1-\text { slope })}$

where $\mathrm{C}^{\text {Std }}$ is known and constant.

Equation 2 represents an example using the equation 1 to calculate the Ca concentration by LIBS for one replicate of sample 1 . The signal used was the height and normalization 9 (C I $193.09 \mathrm{~nm}$ ).

$\mathrm{C}^{\mathrm{Sam}}=\frac{0.503 \times 0.707 \% \mathrm{~m} \mathrm{~m}^{-1}}{(1-0.503)}=0.715 \% \mathrm{~m} \mathrm{~m}^{-1}$

In order to evaluate the contribution of the errors related to the linear model calculated, an analysis of variance (ANOVA) was performed for each replicate. The uncertainty obtained was propagated and a $95 \%$ of confidence was applied to the final value. The values of uncertainty and RSD were calculated for three replicates, for each sample and normalization (see calculations in the SI section).

The concentration values on Table 2 are the average among the replicates. According to the reference values (ICP OES), the trueness was calculated and a range from 60 to $120 \%$ was considered as acceptable result. All the figures of merit mentioned are presented in Table 2, with normalization and signal type for each sample chosen according to acceptable results of trueness and RSD. The outstanding normalizations were selected according to the nearest trueness values of $100 \%$ and the range of slope was demonstrated in Table 2. The unknown concentrations for the samples were calculated using MEC (equation 1). For Ca, all the samples analyzed by LIBS showed values of trueness between 81 and $103 \%$ and values of RSD from 16 to $56 \%$.

For sample S1, for example, the best results for $\mathrm{Ca}$ were obtained with normalization 9 (normalization by C I 193.09), but similar (trueness from 60 to 120\%) results were also obtained for normalizations 1, 5, 10,11 and 12 . The obtained Ca concentration combining LIBS and MEC for sample S1 was $1.08 \% \mathrm{~m} \mathrm{~m}^{-1}$ with an uncertainty $(95 \%$ of confidence level) of $0.18 \% \mathrm{~m} \mathrm{~m}^{-1}$.

The IS method is applied to correct matrix-effect problems, but is currently used to improve the precision and accuracy if some variations during the analysis occur (i.e., transport, vapor generation, plasma temperature). ${ }^{37,50}$ In addition, IS must have similar characteristics, such 

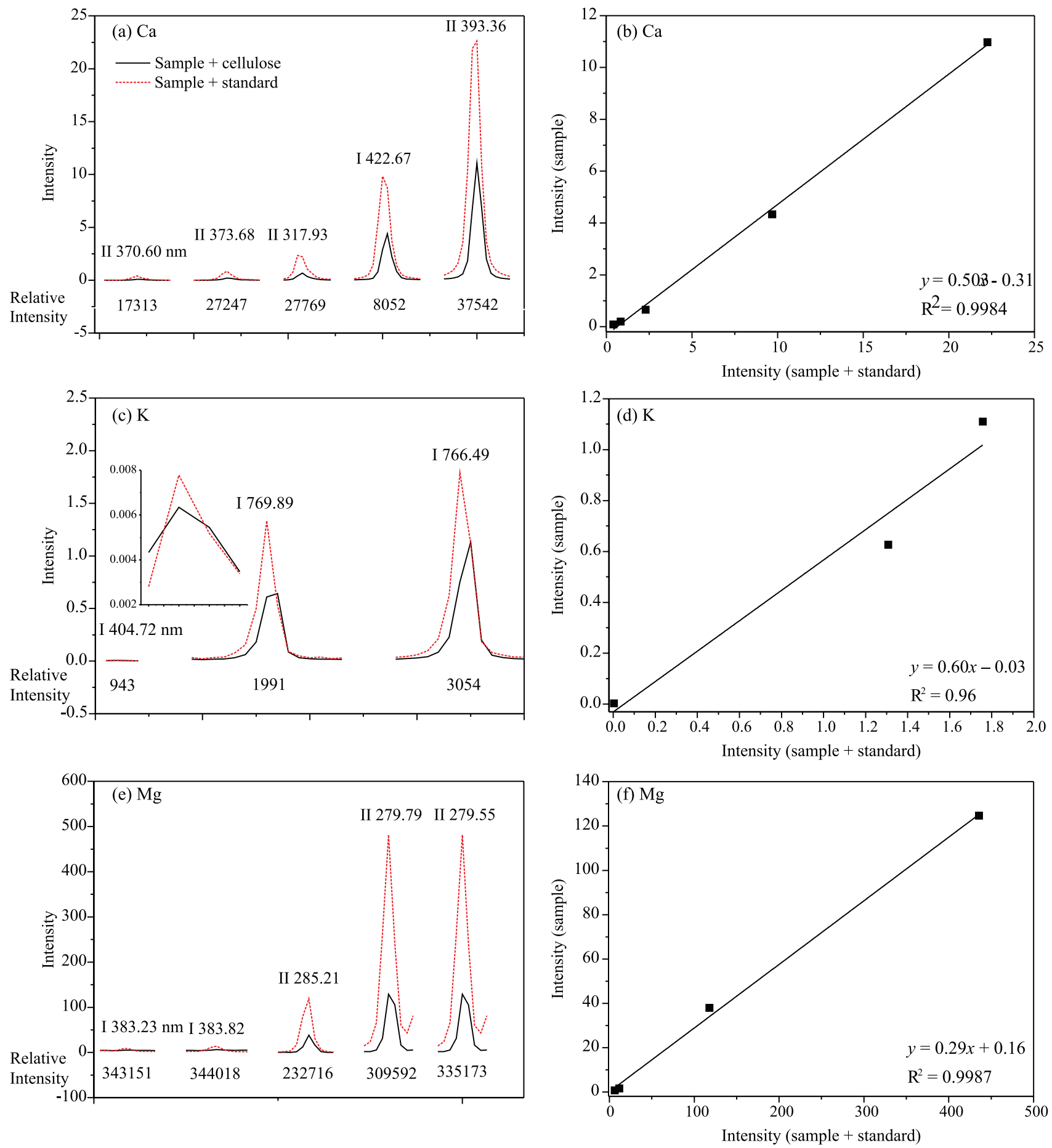

Figure 2. Selected and linear models for (a, b) Ca; (c, d) K and (e, f) Mg for sample 1.

as the atomic mass and/or first ionization potential and homogenous distribution in sample and standard material. ${ }^{51}$ The selection and use of IS in solid analysis is not an easy task. In situations, as such the presented in this study, the use of elements naturally present in the sample composition is an alternative. All samples are carbon-rich due to the natural presence of this element and by addition of cellulose. In this sense, carbon was used as option for
IS. ${ }^{17}$ In Table 2, it is possible to note that the use of IS was satisfactory for $\mathrm{Ca}$ (normalizations 9, 10,11 and 12). The other normalizations, including the signal average (1), presented unsatisfactory results with trueness values higher than $150 \%$ for the majority of the samples.

The same situation occurs for K, but only for the samples S3 and S5, with trueness of 95 and 109\%, respectively. For the analyte $\mathrm{K}$, there is a problem regarding 
Table 2. Normalizations and figures of merit for the LIBS analysis using MEC as calibration method

\begin{tabular}{|c|c|c|c|c|c|c|c|c|c|c|}
\hline Analyte & Sample & Data & $\begin{array}{c}\text { Normalization type } \\
\text { remark }^{\mathrm{a}}\end{array}$ & Slope range & $\begin{array}{l}\text { LIBS }^{\mathrm{b}} / \\
\left(\% \mathrm{~m} \mathrm{~m}^{-1}\right)\end{array}$ & Uncertainty & $\mathrm{RSD} / \%$ & $\begin{array}{l}\text { ICP OES / } \\
\left(\% \mathrm{~m} \mathrm{~m}^{-1}\right)\end{array}$ & Trueness / \% & $\begin{array}{r}\text { Trueness } \\
\text { range / \% }\end{array}$ \\
\hline \multirow{6}{*}{$\mathrm{Ca}$} & $\mathrm{S} 1$ & height & $\begin{array}{l}\text { 9: C I } 193.09 \mathrm{~nm} \\
(1,5,10,11,12)^{\mathrm{c}}\end{array}$ & $0.50-0.69$ & 1.08 & 0.18 & 20 & 1.13 & 96 & \multirow{6}{*}{$81-103$} \\
\hline & $\mathrm{S} 2$ & area & $\begin{array}{c}\text { 11: C I } 247.85 \mathrm{~nm} \\
(1,4,9,10,12)^{\mathrm{c}}\end{array}$ & $0.55-0.67$ & 1.20 & 0.19 & 16 & 1.49 & 81 & \\
\hline & $\mathrm{S} 3$ & height & $\begin{array}{l}\text { 9: C I } 193.09 \mathrm{~nm} \\
(1,5,10,11,12)^{\mathrm{c}}\end{array}$ & $0.39-0.43$ & 0.49 & 0.23 & 47 & 0.49 & 100 & \\
\hline & $\mathrm{S} 4$ & area & $\begin{array}{l}\text { 11: C I } 247.85 \mathrm{~nm} \\
(9,10,12)^{\mathrm{c}}\end{array}$ & $0.30-0.38$ & 0.36 & 0.20 & 56 & 0.35 & 103 & \\
\hline & S5 & height & $\begin{array}{l}\text { 11: C I } 247.85 \mathrm{~nm} \\
(2,9,10,12)^{c}\end{array}$ & $0.50-0.59$ & 0.90 & 0.21 & 23 & 1.02 & 88 & \\
\hline & S6 & height & $\begin{array}{l}\text { 9: C I } 193.09 \mathrm{~nm} \\
(1,5,10,11,12)^{\mathrm{c}}\end{array}$ & $0.49-0.43$ & 0.60 & 0.21 & 36 & 0.71 & 85 & \\
\hline \multirow{6}{*}{ K } & $\mathrm{S} 1$ & height & 11: C I $247.85 \mathrm{~nm}$ & $0.60-0.77$ & 1.39 & 5.8 & 414 & 0.73 & 199 & \multirow{6}{*}{$95-109$} \\
\hline & $\mathrm{S} 2$ & height & 9: C I $193.09 \mathrm{~nm}$ & $0.67-1.56$ & -2.19 & 0.97 & 45 & 1.23 & -178 & \\
\hline & $\mathrm{S} 3$ & area & $\begin{array}{l}\text { 5: sum } \\
(1)^{\mathrm{c}}\end{array}$ & $0.33-0.44$ & 0.40 & 0.41 & 180 & 0.42 & 95 & \\
\hline & S4 & height & 11: C I $247.85 \mathrm{~nm}$ & $1.10-1.71$ & -2.92 & 0.5 & 17 & 0.92 & -317 & \\
\hline & S5 & area & $\begin{array}{l}\text { 11: C I } 247.85 \mathrm{~nm} \\
(9,10,12)^{\mathrm{c}}\end{array}$ & $0.22-0.54$ & 0.37 & 0.66 & 175 & 0.34 & 109 & \\
\hline & S6 & area & 11: C I $247.85 \mathrm{~nm}$ & $0.71-0.89$ & 2.71 & 0.56 & 20 & 1.43 & 189 & \\
\hline \multirow{6}{*}{$\mathrm{Mg}$} & $\mathrm{S} 1$ & height & $\begin{array}{l}\text { 8: individual spectrum } \\
\text { maximum }+ \text { sum } \\
(2,4,6)^{\mathrm{c}}\end{array}$ & $0.27-0.29$ & 0.07 & 0.009 & 13 & 0.07 & 100 & \multirow{6}{*}{$74-106$} \\
\hline & $\mathrm{S} 2$ & height & $\begin{array}{l}\text { 4: individual spectrum } \\
\text { maximum + average } \\
\quad(2,3,6,7,8)^{\mathrm{c}}\end{array}$ & $0.33-0.46$ & 0.11 & 0.01 & 9 & 0.13 & 85 & \\
\hline & $\mathrm{S} 3$ & height & $\begin{array}{l}\text { 2: norm and average } \\
(6)^{c}\end{array}$ & $0.21-0.29$ & 0.059 & 0.004 & 6 & 0.08 & 74 & \\
\hline & S4 & height & $\begin{array}{c}\text { 10: C I } 247.85 \mathrm{~nm} \\
(2,6,9,11,12)^{\mathrm{c}}\end{array}$ & $0.36-0.40$ & 0.11 & 0.02 & 16 & 0.13 & 85 & \\
\hline & S5 & area & $\begin{array}{l}\text { 12: C I } 247.85 \mathrm{~nm} \\
(6,9,10,11)^{\mathrm{c}}\end{array}$ & $0.45-0.49$ & 0.16 & 0.03 & 22 & 0.16 & 100 & \\
\hline & S6 & area & $\begin{array}{l}\text { 3: area and average } \\
(7)^{c}\end{array}$ & $0.46-0.54$ & 0.18 & 0.05 & 26 & 0.17 & 106 & \\
\hline
\end{tabular}

The numbers in parentheses refer to the normalizations 1 (average), 2 (norm and average), 3 (area and average), 4 (individual spectrum maximum and average), 5 (sum), 6 (norm and sum), 7 (area and sum), 8 (individual spectrum maximum and sum), 9 (C I 193.09 nm as internal standard (IS) and average), 10 (C I $193.09 \mathrm{~nm}$ as IS and sum), 11 (C I $247.85 \mathrm{~nm}$ as IS and average) and 12 (C I $247.85 \mathrm{~nm}$ as IS and sum). I and II refer to the atomic and ionic emission lines, respectively; ${ }^{\mathrm{b}}$ concentration calculated for LIBS using equation 1; ${ }^{\mathrm{c}}$ normalizations with trueness values in the range of 60 to $120 \%$. LIBS: laser-induced breakdown spectroscopy; RSD: relative standard deviation; ICP OES: inductively coupled plasma optical emission spectrometry.

the emission lines, because only four are available in the studied spectral range (186-1042 $\mathrm{nm}$ ). In this case, were possible to obtain only signals for the first two (Figure 2) most intense lines. The emission line $404.72 \mathrm{~nm}$ presented analytical signals with low signal-to-noise ratio (SNR). Even with the satisfactory results for the samples mentioned previously, no results for $\mathrm{K}$ are reliable, since the linear models has only 2 points.

From the eight emission lines tested for $\mathrm{Mg}$, three presented spectral interferences $(280.27,517.27$ and
$518.36 \mathrm{~nm}$ ) and were not considered for the linear model. For this analyte, the trueness values were from 74 to $106 \%$ and the RSD were from 6 to $26 \%$. In this case, the best normalizations were not only for C as IS, but also for norms 2, 3, 4 and 8. All these values were extremely satisfactory, and matrix effect was not observed.

Differences between the atomization and ionization process of these three analytes $(\mathrm{Ca}, \mathrm{K}$ and $\mathrm{Mg}$ ) and $\mathrm{C}$ as IS, can be associated with the results. ${ }^{52}$ As mentioned before, one condition to obtain an ideal IS are the similar values 
of first ionization potential. For $\mathrm{C}$ the potential is $11.26 \mathrm{eV}$, greatly different from $\mathrm{Ca}, \mathrm{K}$ and $\mathrm{Mg}$ (6.11-9.39 eV). This observation can be one of the reasons why $\mathrm{C}$ did not work so well as IS for $\mathrm{Mg}$, but according to Kuznetsova and Morgulis, ${ }^{53}$ just factors as the ionization potentials, excitation energies and similar thermal properties are not enough to have success using the IS.

As expected, all the slope values were below one and similar for $\mathrm{Ca}$ and $\mathrm{Mg}$, ranging from 0.30 to 0.69 for $\mathrm{Ca}$ and from 0.24 to 0.48 for $\mathrm{Mg}$. For $\mathrm{K}$, the slope values were higher than those observed for $\mathrm{Ca}$ and $\mathrm{Mg}$, with only two exceptions, S3 and S5 (samples that obtained acceptable trueness values). This observation can be due to the reduced number of emission lines observed for $\mathrm{K}$.

A comparison between MEC and one-point gravimetric standard addition calibration (OP GSA) was performed. The OP GSA is a calibration method that approaches the same principle of MEC: matrix-matching, but in this case the method uses only one emission line, where the unknown concentration is calculated by curve extrapolation..$^{54,55}$

The figure of merit values for the LIBS analysis using the OP GSA are shown in Table S3 (SI section). The emission lines that presented the best results in the MEC were also used for the OP GSA models; besides RSD and trueness, calculations of $\mathrm{F}$ test were performed to verify the curve linearity. Table S3 (SI section) shows the ratio of $\mathrm{F}_{\text {calculated }} / \mathrm{F}_{\text {tabulated }}$. For $\mathrm{Ca}$, the emission line $393.36 \mathrm{~nm}$ was better than the others, with trueness varying from 82 to $110 \%$ and RSD from 3 to $29 \%$. For K (766.49 nm emission line), the trueness values were within the acceptable range only for S3 and S8 with 111 and 105\% and RSD of 8 and $19 \%$, respectively. The best emission line for $\mathrm{Mg}$ was $279.55 \mathrm{~nm}$, where the trueness values varied from 82 to $108 \%$ and RSD from 4 to $8 \%$, except for S2. The values of F-test ratio were high $\left(\mathrm{F}_{\text {calculated }}\right.$ higher than $\left.\mathrm{F}_{\text {tabulated }}\right)$ showing that the OP GSA models are linear, except for Mg of S2 (ratio of 2) which presented a low trueness, being explained by lack of linearity.

The three analytes presented good results for the most intense emission lines: Ca 393.36, K 766.49 for few samples and Mg $279.55 \mathrm{~nm}$ for the majority of the samples. When these results are compared with MEC (see Table 2), the obtained one presented also good trueness for all samples and analytes. In addition, MEC showed a capacity to circumvent interferences related to matrix and spectral effects. This observation is clear for sample S2 when Mg was determined: the trueness for MEC and OP GSA were 85 (see Table 2) and 49\% (see Table S3, SI section), respectively.

An additional test with different proportions of analytes into the stock mixture was proposed to evaluate if variations can negatively interfere and generate a matrix effect. Four stock mixtures were prepared and mixed with $\mathrm{S} 1$. A triplicate $(\mathrm{n}=3)$ for each stock mixture with S1 was pelletized and analyzed by LIBS and ICP OES and the data was calculated following all the procedures proposed in this study. Table 3 shows the concentration values for each analyte and its ratio. The signal normalization modes selected were the same as described in Table 2.

Table 3. Normalizations and figures of merit for the LIBS analysis using MEC for sample S1 and different stock mixtures

\begin{tabular}{lccc}
\hline $\begin{array}{l}\text { Stock } \\
\text { mixture }\end{array}$ & $\begin{array}{c}\text { Concentration in } \\
\text { stock mixture / } \\
\left(\% \mathrm{~m} \mathrm{~m}^{-1}\right)\end{array}$ & $\begin{array}{c}\text { Ratio among } \\
\text { the analytes }\end{array}$ & Trueness / \% \\
\hline 1 & $0.66(\mathrm{Ca})$ & 3.7 & 92 \\
& $0.68(\mathrm{~K})$ & 3.7 & -7793 \\
\hline & $0.18(\mathrm{Mg})$ & 1 & 105 \\
\hline & $0.35(\mathrm{Ca})$ & 1.9 & 80 \\
3 & $0.60(\mathrm{~K})$ & 3.3 & 120 \\
& $0.18(\mathrm{Mg})$ & 1 & 89 \\
\hline & $0.72(\mathrm{Ca})$ & 4 & -24 \\
& $0.26(\mathrm{~K})$ & 1.4 & 106 \\
\hline & $0.18(\mathrm{Mg})$ & 1 & 92 \\
& $0.72(\mathrm{Ca})$ & 8 & 124 \\
& $0.59(\mathrm{~K})$ & 3.2 & 81 \\
\hline & $0.09(\mathrm{Mg})$ & 1 & \\
\hline
\end{tabular}

The similarity of trueness values demonstrates that even changing the proportions of analytes in a stock mixture did not interfere in the results. In the specific case of $\mathrm{Ca}$ and $\mathrm{Mg}$ it was observed a good concordance with those results presented in Table 2. In the case of K, the results were not consistent due to the lack of emission lines available in the studied range.

Trueness values between 60 and $120 \%$ were obtained and, consequently, the efficiency of MEC with the spectral normalizations sort out matrix effect issues.

\section{Conclusions}

The use of MEC with LIBS is a suitable alternative of calibration for dietary supplements, due to matrix effect of these products. The results obtained for $\mathrm{Ca}$ and $\mathrm{Mg}$ were satisfactory with recovery between 60 and $120 \%$. However, due to limitation of few emission lines for $\mathrm{K}$, a reliable calibration model was not possible to obtain. For $\mathrm{Ca}$, the possibility of using $\mathrm{C}$ was successfully exploited improving the precision and accuracy, and for $\mathrm{Mg}$ other normalizations also improved these figures of merit. In general, with MEC and the normalization, it is possible to observe spectral interferences in the linear models, avoid 
matrix effect due to matrix matching and improve results of precision and trueness.

\section{Supplementary Information}

Supplementary information is available free of charge at http://jbcs.sbq.org.br as PDF file.

\section{Acknowledgments}

This study was supported by Fundação de Amparo à Pesquisa do Estado de São Paulo (FAPESP) $\mathrm{PhD}$ grants 2014/11415-0 to A. S. A. and 2016/17221-8 to J. P. C., and grant 2016/01513-0. The authors are also grateful to the Conselho Nacional de Desenvolvimento Científico e Tecnológico (CNPq) grants 401074/2014-5, 305637/2015-0 and PhD grant 160152/2015-1 to M. A. S. This study was financed in part by the Coordenação de Aperfeiçoamento de Pessoal de Nível Superior, Brasil (CAPES), Finance Code 001.

\section{References}

1. Mermet, J. M.; Spectrochim. Acta, Part B 2010, 65, 509.

2. Koscielniak, P.; Wieczorek, M.; Anal. Chim. Acta 2016, 944 , 14.

3. Khan, N.; Jeong, I. S.; Hwang, I. M.; Kim, J. S.; Choi, S. H.; Nho, E. Y.; Choi, J. Y.; Kwak, B. M.; Ahn, J. H.; Yoon, T.; Kim, K. S.; Food Chem. 2013, 141, 3566.

4. Avula, B.; Wang, Y. H.; Duzgoren-Aydin, N. S.; Khan, I. A.; Food Chem. 2011, 127, 54.

5. Santos, J.; Oliva-Teles, M. T.; Delerue-Matos, C.; Oliveira, M. B. P. P.; Food Chem. 2014, 151, 311.

6. Hedegaard, R. V.; Rokkjær, I.; Sloth, J. J.; Anal. Bioanal. Chem. 2013, 405, 4429.

7. Welna, M.; Szymczycha-Madeja, A.; Food Chem. 2014, 159, 414.

8. Pereira, C. C.; de Souza, A. O.; Oreste, E. Q.; Vieira, M. A.; Ribeiro, A. S.; Food Chem. 2018, 240, 959.

9. Alves, M. M.; Medina, A. L.; Pinto, A. M. T.; Antunes, A. C. N.; Sanches Filho, P. J.; Ribeiro, A. S.; Vieira, M. A.; J. Braz. Chem. Soc. 2018, 29, 285.

10. Augusto, A. S.; Batista, E. F.; Pereira-Filho, E. R.; Anal. Methods 2016, 8, 5851.

11. Batista, É. F.; Augusto, A. S.; Pereira-Filho, E. R.; Talanta 2016, 150, 206.

12. Costa, V. C.; de Babos, D. V.; de Aquino, F. W. B.; Virgílio, A.; Amorim, F. A. C.; Pereira-Filho, E. R.; Food Anal. Methods 2017, 11, 1886.

13. Nobrega, J. A.; Trevizan, L. C.; Araujo, C. L. G.; Nogueira, A. R. A.; Spectrochim. Acta, Part B 2002, 57, 1855.
14. Costa, L. M.; Silva, F. V.; Gouveia, S. T.; Nogueira, A. R. A.; Nobrega, J. A.; Spectrochim. Acta, Part B 2001, 56, 1981.

15. Szymczycha-Madeja, A.; Welna, M.; Pohl, P.; Food Chem. 2014, 146, 220.

16. Chirinos, J.; Oropeza, D.; González, J. J.; Zorba, V.; Russo, R. E.; Appl. Spectrosc. 2017, 71, 709.

17. Nunes, M. A. G.; Voss, M.; Corazza, G.; Flores, E. M. M.; Dressler, V. L.; Anal. Chim. Acta 2016, 905, 51.

18. Lauwens, S.; Costas-Rodríguez, M.; Vanhaecke, F.; Anal. Chim. Acta 2018, 1025, 69.

19. Tormen, L.; Torres, D. P.; Dittert, I. M.; Araújo, R. G. O.; Frescura, V. L. A.; Curtius, A. J.; J. Food Compos. Anal. 2011, $24,95$.

20. Cho, H. H.; Kim, Y. J.; Jo, Y. S.; Kitagawa, K.; Arai, N.; Lee, Y. I.; J. Anal. At. Spectrom. 2001, 16, 622.

21. Szymczycha-Madeja, A.; Welna, M.; Food Chem. 2013, 141, 3466.

22. Niu, L.; Cho, H. H.; Song, K. S.; Cha, H.; Kim, Y.; Lee, Y. I.; Appl. Spectrosc. 2002, 56, 1511.

23. Jesus, J. P.; Suárez, C. A.; Ferreira, J. R.; Giné, M. F.; Talanta 2011, 85, 1364.

24. Serapinas, P.; Labarraque, G.; Charlet, P.; Ežerinskis, Ž.; Juzikiene, V.; J. Anal. At. Spectrom. 2010, 25, 624.

25. Mukhono, P. M.; Angeyo, K. H.; Dehayem-Kamadjeu, A.; Kaduki, K. A.; Spectrochim. Acta, Part B 2013, 87, 81.

26. Bro, R.; Anal. Chim. Acta 2003, 500, 185.

27. Gómez-Nubla, L.; Aramendia, J.; Vallejuelo, S. F.-O.; Madariaga, J. M.; Microchem. J. 2018, 137, 392.

28. Augusto, A. S.; Barsanelli, P. L.; Pereira, F. M. V.; Pereira-Filho, E. R.; Food Res. Int. 2017, 94, 72.

29. Costa, V. C.; Aquino, F. W. B.; Paranhos, C. M.; Pereira-Filho, E. R.; Waste Manage. 2017, 70, 212.

30. Jones, W. B.; Donati, G. L.; Calloway, C. P.; Jones, B. T.; Anal. Chem. 2015, 87, 2321.

31. Goncalves, D. A.; McSweeney, T.; Santos, M. C.; Jones, B. T.; Donati, G. L.; Anal. Chim. Acta 2016, 909, 24.

32. Virgilio, A.; Schiavo, D.; Nóbrega, J. A.; Donati, G. L.; J. Anal. At. Spectrom. 2016, 31, 1216.

33. Fortunato, F. M.; Vieira, A. L.; Gomes Neto, J. A.; Donati, G. L.; Jones, B. T.; Microchem. J. 2017, 133, 76.

34. Donati, G. L.; Amais, R. S.; Nóbrega, J. A.; J. Anal. At. Spectrom. 2011, 26, 1827.

35. Amais, R. S.; Nóbrega, J. A.; Donati, G. L.; J. Anal. At. Spectrom. 2014, 29, 1258.

36. Donati, G. L.; Amais, R. S.; Nóbrega, J. A.; J. Anal. At. Spectrom. 2012, 27, 1274.

37. Virgilio, A.; Gonçalves, D. A.; McSweeney, T.; Gomes Neto, J. A.; Nóbrega, J. A.; Donati, G. L.; Anal. Chim. Acta 2017, 982, 31.

38. Augusto, A. S.; Sperança, M. A.; Andrade, D. F.; Pereira-Filho, E. R.; Food Anal. Methods 2017, 10, 1515. 
39. Chinni, R.; Cremers, D. A.; Multari, R.; Appl. Opt. 2010, 49, C143.

40. Hahn, D. W.; Omenetto, N.; Appl. Spectrosc. 2012, 66, 347.

41. Fortes, F. J.; Moros, J.; Lucena, P.; Cabalin, M. L.; Laserna, J. J.; Anal. Chem. 2014, 15, 245.

42. Pasquini, C.; Cortez, J.; Silva, L. M. C.; Gonzaga, F. B.; J. Braz. Chem. Soc. 2007, 18, 463.

43. Costa, V. C.; Castro, J. P.; Andrade, D. F.; Babos, D. V.; Garcia, J. A.; Sperança, M. A.; Catelani, T. A.; Pereira-Filho, E. R.; TrAC, Trends Anal. Chem. 2018, 108, 65.

44. Andrade, D. F.; Pereira-Filho, E. R.; Konieczynski, P.; J. Braz. Chem. Soc. 2017, 28, 838.

45. Andrade, D. F.; Pereira-Filho, E. R.; J. Agric. Food Chem. 2016, 64, 7890.

46. Castro, J. P.; Pereira-Filho, E. R.; J. Anal. At. Spectrom. 2016, 31, 2005.

47. The MathWorks, Inc.; MATLAB 2017b; The MathWorks, Inc., Natick, MA, USA, 2017.
48. Sezer, B.; Bilge, G.; Boyaci, I. H.; TrAC, Trends Anal. Chem. 2017, 97, 345.

49. Sperança, M. A.; Pomares-Alfonso, M. S.; Pereira-Filho, E. R.; Anal. Methods 2018, 10, 533.

50. Kościelniak, P.; Wieczorek, M.; Anal. Chim. Acta 2016, 944 , 14.

51. Frick, D. A.; Günther, D.; J. Anal. At. Spectrom. 2012, $27,1294$.

52. Braga, J. W. B.; Trevizan, L. C.; Nunes, L. C.; Rufini, I. A.; Santos, D.; Krug, F. J.; Spectrochim. Acta, Part B 2010, 65, 66.

53. Kuznetsova, A.; Morgulis, T. E.; J. Anal. At. Spectrom. 1988, 3, 973.

54. Bader, M.; J. Chem. Educ. 1980, 57, 703.

55. Gao, Y.; Sturgeon, R. E.; Mester, Z.; Hou, X.; Zheng, C.; Yang, L.; Anal. Chem. 2015, 87, 7996.

Submitted: June 22, 2018

Published online: October 22, 2018 